Working Paper 9606

\title{
COMMITMENT AS INVESTMENT UNDER UNCERTAINTY
}

by Joseph A. Ritter and Joseph G. Haubrich

Joseph A. Ritter is a senior economist at the Federal Reserve Bank of St. Louis. Joseph G. Haubrich is a consultant and economist at the Federal Reserve Bank of Cleveland. The authors thank Avinash Dixit and seminar participants at North Carolina State University, the University of Pittsburgh, and the Federal Reserve Bank of Atlanta for helpful comments.

Working papers of the Federal Reserve Bank of Cleveland are preliminary materials circulated to stimulate discussion and critical comment. The views stated herein are those of the authors and are not necessarily those of the Federal Reserve Bank of Cleveland or of the Board of Governors of the Federal Reserve System.

Working papers are now available electronically through the Cleveland Fed's home page on the World Wide Web: http://www.clev.frb.org.

August 1996 


\begin{abstract}
Irreversible investment and the techniques associated with pricing real options have led to significant advances many areas. We broaden this range of applications, showing how the techniques can apply to many policy problems in finance, macroeconomics, and trade policy. With small changes, standard techniques can handle a wide range of strategic problems related to policy. The decision to commit is like the decision to make an irreversible investment. Explicitly considering and correctly valuing the option to wait makes discretion relatively more attractive, implies that greater uncertainty increases the gain to discretion and results in policy that displays hysteresis.
\end{abstract}




\section{Introduction}

Irreversible investment and the techniques associated with pricing real options have led to significant advances in capital budgeting, environmental economics, and industrial organization. We wish to broaden this range of applications further, showing how the techniques can apply to many game theoretic problems in finance, macroeconomics, and trade policy. We show how, with small changes, standard techniques can handle a wide range of strategic problems related to policy.

More specifically, we consider problems of commitment. The decision to commit is like the decision to make an irreversible investment. The previous literature on commitment considers a once-and-for-all choice between rules and discretion, and does not allow future agents to adopt rules. If the option to wait indeed has positive value--as such options often do--it adds to the desirability of discretion. Furthermore, because no policymaker can bind itself forever, we extend the analysis to consider entry and exit; not from production, but from commitment to a policy rule.

Our paper proceeds as follows. Section II discusses a variety of models that fit the general framework we propose. It looks at the static games that section III embeds in continuous time. We choose games where commitment is sometimes useful, that is, where the standard NCE (noncooperative equilibrium, or Nash-Cournot equilibrium) leads to a Pareto inferior outcome. Section III provides a very general way of thinking about policy, allowing costly commitment with costly reversal. Continuous time highlights the analogy with irreversible investment problems, as well as simplifying the model. We illustrate how decisions to commit or renege depend on the cost of doing so and on uncertainty in the environment. 
In section IV, we conclude by emphasizing three general results. First, the option to wait, which we have restored to the policymaker's decision problem, makes commitment less attractive and also implies that increased uncertainty makes commitment even less so. This is the "bad news principle" of irreversible investment applied in a policy context. Second, by allowing the commitment decision to take place in "real time," we note that the policy choice process displays hysteresis; the policy in force at a given time depends on history, not just the prevailing state. Third, we show that the ability to switch regimes means that small changes in the underlying state can induce large changes in the relevant expectations; consequently, variables sensitive to expectations (such as asset prices) can move quickly and asymmetrically, showing a decided nonlinearity.

\section{Preliminary Examples}

In this section, we present several concrete examples in which commitment matters and regret is possible. We begin with one from bank regulation. The banking focus also shows how to use irreversibility for policy rather than investment decisions (see Pindyck [1991] or McDonald and Siegel [1986]).

\section{Bank Regulation}

Consider the following game between a regulator and a bank (or the banking system). The regulator may choose to be either tough (T) or weak (W). Tough regulators do not bail out insolvent banks; weak regulators do. A bank chooses to be safe (S) or risky (R). If banks are truly safe, the regulator prefers to relax his vigilance, take it easy, 
and be weak. If banks are risky, the regulator prefers to be tough. If the regulator is tough, banks have an incentive to stay safe, but if the regulator is weak, they would rather choose risky. The strategic form of the game then looks like (G0).

(G0) Payoffs for Game between Regulator and Banks

\begin{tabular}{|l|lll|}
\hline & & Banks & \\
\hline & & Safe & Risky \\
Regulator & Tough & 0,0 & $-8,-4$ \\
& Weak & $4,-8$ & $-8,-7$ \\
\hline
\end{tabular}

(See Mailath and Mester [1994] or Kane [1989] for more sophisticated approaches to closure policy, which do not, however, address the dynamic commitment problem.) The NCE is (Weak, Risky) but both parties would prefer (Tough, Safe). The regulator can accomplish this by committing to play tough, binding itself to play $\mathrm{T}$ no matter what happens. ${ }^{1}$ With a regulator dedicated to playing T, banks will choose S. Hence the value of commitment. ${ }^{2}$

\footnotetext{
${ }^{1}$ The notion behind this game is that tough regulators will not bail out an insolvent bank, leading the banks to undertake safe investments that make bail-outs unnecessary. A weak regulator will bail out the banks, and so banks choose the more profitable risky investment; some fail, and the regulator must bail them out. ${ }^{2}$ Those familiar with game theory may notice that this is a game in which the Row player has "staying power." In the standard classification of the 78 distinct bimatrix games, it is Brams Number 68. A similar game, Brams Number 63, would suit our purposes as well. See Brams (1983).
} 
Now let's complicate the example by bringing in the possibility of regret. So far, the regulator is always happy about committing to be tough. Suppose, however, that in some states of the world, the regulator regrets this. In good states, we prefer a tough regulator who eliminates the costly wealth transfers from taxpayers to bank investors, but in bad states, we prefer the weak regulator. Perhaps in the bad state (say a recession), systemic risk means that being tough leads to a financial panic.

(G1) Payoff Functions for Game between Regulator and Banks

\begin{tabular}{|llll|}
\hline & & Banks & \\
\hline \multirow{3}{*}{ Regulator } & Tough & $-u^{2},-u^{2}$ & Risky \\
& Weak & $+4-u^{2},-8-u^{2}$ & $-8-u^{2},-4-u^{2}$ \\
& & & $-8-0.5 u^{2},-7-0.5 u^{2}$ \\
\hline
\end{tabular}

For small values of $u$, this game has the same equilibrium as (G0), to which it reduces when $u$ is zero. This game has a "Prisoner's Dilemma" flavor about it for small values of $u$, in that both parties would very much prefer the Tough, Safe payoff. For large shocks to the economy, however (that is, for large $u$ ), the Weak, Risky equilibrium becomes preferable--perhaps reflecting that in a systemic crisis, we need to bail out the 
banks, even if that means they make riskier investments. ${ }^{3}$ In this case, the regulator would regret any commitment to a fixed rule of being tough.

In the next section, we derive the optimal policy when $u$ follows a more general process and when the regulator has a cost of committing and a cost of reneging on that commitment, but some central insights arise if we consider a simple two-state example, with $u=0$ or $u=6$.

Because the policy decision takes place in real time, we have two cases to consider. Either the economy starts out in the good state, or it starts out in the bad state. Suppose it starts out in the good state. If the regulator is weak, he gets a payoff of -8 today and chooses whether to be weak again or tough next period. If the regulator is tough, he gets a payoff of 0 today and remains tough forever, as the only way to be tough is to commit forever. This immediately shows where the option value enters: By being weak today, the regulator retains the option to commit tomorrow, and this option has value. The analogy with irreversible investment is direct.

The standard time-consistency literature, however, considers rules versus discretion as a once-and-for-all choice. Unless the regulator commits to rules at the beginning of time, the suboptimal or "weak" choice is made in each period. Making such a decision forever seems simple-minded in this simple model, yet it is analogous to the restriction implied by posing the rules-versus-discretion question in the standard way. Drawing the analogy to investment under uncertainty highlights a flaw in the standard approach.

\footnotetext{
${ }^{3}$ Section III uses positive and negative shocks. In this example, it doesn't really make sense to consider $u<0$. Section III could easily accommodate one-sided shocks by using geometric Brownian motion.
} 
A striking consequence of the option value--the bad news principle--also arises in this example. We suspect this principle lies behind a tendency that is conspicuous in the arguments over rules versus discretion. The rhetoric advocating discretion accentuates the negative possibilities--the downside, the worst outcomes--of rules.

In this example, the bad news principle arises because the regulator sometimes regrets the commitment to be tough. The regulator never regrets an initial decision to be weak, since it can later commit to be tough. Increasing the payoff to toughness does not affect the relative payoffs--and thus the choice--today. This illustrates the principle that only news about bad outcomes affects the choice between rules and discretion.

The above formulation differs from the standard approach in a more subtle way, necessary, but not sufficient, for irreversibility. The standard approach makes a timeless comparison before the state of the economy is fully known. By contrast, in this paper the government operates in "real time" and knows the current state of the economy, just as in the irreversible investment literature the investor knows today's rate of return. Again, this twist follows naturally from the investment analogy.

Continuing the example shows how the standard timeless comparison can lead to the wrong conclusion by ignoring information the government can use. The standard approach gives the regulator two strategies: Either commit to Tough or allow discretion, which in our simple example amounts to playing Weak forever.

The regulator, though, has another possibility. Operating in real time, the regulator can observe the economy and chose rules or discretion. If the good state turns up, the regulator should be tough. If the bad state occurs, the regulator chooses Weak today and chooses again next period. 
Macroeconomic Policy

A game with a somewhat different flavor is presented in (G2).

(G2) Payoffs for Game between Fed and Treasury

\begin{tabular}{|llll|}
\hline & & Treasury & \\
\hline & & Tight & Easy \\
Fed & Tight & $2-\mathrm{u}^{2}, 1-\mathrm{u}^{2}$ & $-3 \mathrm{u}^{2},-3 \mathrm{u}^{2}$ \\
& Easy & $-3 \mathrm{u}^{2},-3 \mathrm{u}^{2}$ & $0.5-0.5 \mathrm{u}^{2}, 1.5-0.5 \mathrm{u}^{2}$ \\
\hline
\end{tabular}

This is a version of the game known as "Chicken" or "Battle of the Sexes." Its clearest macroeconomic interpretation was presented by Sargent (1986), who argued in "Reaganomics and Credibility" (1986) that tight monetary policy is compatible with tight fiscal policy but not with easy fiscal policy. Who gives in and accommodates the other's policy, the Fed or the Treasury? In (G2), such a conflict exists for small values of $u$, but easy policy is better for large shocks, and indeed forms a Nash equilibrium. This captures the intuitive idea that, for a massive real shock, easy policy is better. By committing to Tight, the Fed can enforce its preferred equilibrium, but it regrets this choice in times of large shocks.

Pindyck (1977) considered such a coordination problem in greater depth, analyzing a dynamic game between the fiscal and monetary authority, each of which has a different objective in controlling the economy. He did not consider the irreversibility aspect of policy choice. 
In Haubrich and Ritter (1996), we analyze commitment to monetary rules in the traditional time inconsistency setup (Barro and Gordon, [1983]). A third monetary policy application derives from observations about the fragility of fixed-exchange-rate regimes. Obstfeld and Rogoff (1995) lay out the following case: (1) Maintaining a fixed exchange rate is technically feasible for almost any country; (2) under normal circumstances, countries gain (or think they gain) from fixing their exchange rate; but (3) the collateral damage caused by an attempt to defend the peg, when threatened by a terms-of-trade shift or some other shock, means the government's commitment to its rate may not be credible. Thus, even the strongest legal commitments to fixed exchange rates--currency boards, for example--will not always succeed (Zarazaga [1995]). Nevertheless, despite compelling arguments that they will ultimately fail, countries continue to adopt fixedexchange-rate policies. We describe a framework that can provide a positive theory of the switches between policy regimes.

\section{Trade Policy}

Some insight into the dynamics of trade agreements might be gained from (G3). The players are countries, say Argentina and Brazil. Each chooses between high and low tariffs. The noncooperative equilibrium of the game is high tariffs in both countries. Both of them would ordinarily gain by coordinating on low tariffs, and this outcome can be achieved by establishing a free trade area, that is, by committing. But when Brazil experiences a recession, measured by its unemployment rate $u$, its Argentine imports fall, tempting Argentina to leave the free trade area and raise tariffs. Brazil responds by raising its own tariff rate. Because Brazil sees reduced imports as an advantage, its 
payoffs for this game are increasing in $u$. We assume that Argentina's economy is stable, and that Brazil always stands open to the trade pact, so that Argentina effectively decides the extent of free trade. A fully satisfactory model here would clearly involve more symmetry and give Brazil incentives for breaking the trade pact as well. We include it to illustrate the range of problems our approach can address.

(G3) Payoffs in Free Trade Game

\begin{tabular}{|c|c|c|c|}
\hline & & Brazil & \\
\hline & & Low & High \\
\hline \multirow[t]{2}{*}{ Argentina } & Low & $8-u^{2}, 8+u^{2}$ & $-2,9+3 u^{2}$ \\
\hline & High & $9-u^{2},-2$ & 0,0 \\
\hline
\end{tabular}

As mentioned before, the payoff structure of examples (G1), (G2), and (G3) has more general applications. The tractability of the quadratic model makes it a natural approximation for many commitment problems (and for many other economic problems. Thus, we could illustrate our main point with such additional examples as adhering to the Gold Standard (with regret in a war or depression), granting patents for the exclusive use of new technology (with regret in cases like AZT), or allowing constitutions to bind future legislatures. $^{4}$

\footnotetext{
${ }^{4}$ In fact, the tractability constraint does not bind us exclusively to quadratic payoffs. From our perspective, the more binding constraint in the continuous time models was the need to posit an essentially static underlying game. We conjecture that, with sufficient mathematical expertise, this need not be a binding constraint either.
} 


\section{Entering and Exiting Commitment}

Mechanisms to commit irrevocably are almost impossible to imagine. It is not difficult, however, to cite examples of mechanisms that make it costly for a firm or a government to alter its policy. A constitutional amendment, for example, is difficult to pass and to remove. Ordinary legislation has lower costs at both ends. For a firm, the corporate charter, financial agreements, and strategic plans play a similar role.

Institutions can effectively tie their hands loosely or tightly, being able to escape if they are willing to bear the appropriate level of pain. For any particular decision, these costs can usually be considered as given: passing a law, amending the constitution, issuing a regulation. In future work, we hope to make the choice of commitment mechanism endogenous.

We maintain the traditional semantics of commitment and discretion, but wish to highlight a bias in tone that colors the discussion when commitment is not irrevocable. We are forced to use words (like "renege" and "weasel") having clear negative connotations that we regard as unfortunate. We interpret the results of this section as a model of optimal behavior and tolerate the terminology only to fit our paper into the literature on rules and discretion.

A world in which policymakers can, at a cost, enter and exit commitment (or, more generally, any policy regime) closely resembles Dixit's (1989a) model of the entry and exit problem faced by competitive firms. 
While a discrete time approach can sometimes handle particular versions of the problems (as Lambson [1992] does for entry-exit decisions), ${ }^{5}$ the continuous time approach set out in Dixit and Pindyck (1994) generally proves more convenient. A generic quadratic payoff model captures the main points in a context that is simple yet general.

\section{A Quadratic Model}

We implement these ideas in continuous time as follows: The policy authority (the Fed, for example) will be following either rules or discretion. The payoff from discretion, which depends on the state of the economy $u$, is

(1) $P^{D}(u)=d_{0}+d_{1} u+d_{2} u^{2}$.

The payoff from rules is

(2) $P^{R}(u)=r_{0}+r_{1} u+r_{2} u^{2}$.

Following examples (G1) and (G2), and by analogy with the previous sections, we assume that rules tend to be preferred when the shock is small, so that for small $u$, $P^{R}(u)>P^{D}(u)$. We assume that $u$ follows a simple Ito process $d u=\alpha d t+\sigma d z$

where $\alpha$ describes the drift of the process and $\sigma$ denotes its standard deviation, with $d z$ describing a white-noise Wiener process.

The optimal policy switches between the two quadratic payoff functions with cost $C$ of committing to rules, that is, of moving from discretion to rules, and cost $W$ (for

\footnotetext{
${ }^{5}$ For some specialized problems, the discrete time approach is more natural. One workhorse of the dynamic inconsistency literature in macroeconomics, the unanticipated money model, does not easily generalize to
} 
weaseling) of moving from rules to discretion. ${ }^{6}$ To solve this, we employ the general methods of Dixit and Pindyck (1994). Our problem maps most naturally into an entry and exit problem. Unlike the problem for firms, where uncertainty over prices is best modeled by geometric Brownian motion, for many problems two-sided shocks are more natural and therefore are best modeled with Brownian motion, which may turn negative. Weather, oil price shocks, trade flows, and interest rate shifts may all take positive or negative values. Consequently, where Dixit and Pindyck's problem has two boundaries, one price at which the firm enters the market and another price at which the firm exits, our problem has four boundaries: two above zero and two below zero.

In what follows, we derive the differential equations for the value functions, and derive the smooth pasting and value matching conditions necessary for the optimum of this stochastic control problem. The conditions give us the necessary equations to solve numerically for the boundaries between the rules region and the discretion region. Full details can be found in the appendix.

In the interior of the discretion region, the value function for the problem obeys $r V^{D}=P^{D}(u)+\frac{1}{d t} E\left[d V^{D}\right]$.

We apply Ito's Lemma to find the differential equation for the value function $\frac{1}{2} \sigma^{2} V_{u u}{ }^{D}+\alpha V_{u}^{D}-r V^{D}=-P^{D}$.

A similar argument for the interior of the rules region yields the following, in which subscripts denote partial derivatives:

continuous time. We examine it in a companion paper (Haubrich and Ritter [1995]).

${ }^{6}$ Allowing weaseling adds a component similar to the "escape clause" models of Flood and Isard (1988) and Lohman (1992), who consider a cost to renege. In one sense, we generalize those models by allowing a 
$\frac{1}{2} \sigma^{2} V_{u u}^{D}+\alpha V_{u}^{D}-r V^{D}=-P^{R}$.

Each of these is a second-order linear differential equation, and standard solution techniques are available.

In the solution, there are three regions: a rules regions centered about zero for small shocks, and discretion regions for large positive and large negative shocks. This necessitates three solutions to the equations, depending on which region we are in. Each solution takes the form of a general solution plus $S^{R}$ or $S^{D}$, a quadratic particular solution to the differential equation. ${ }^{7}$ For the rules region the solution is

(3) $V^{R}(u)=B_{1} e^{\beta_{1} u}+B_{2} e^{\beta_{2} u}+S^{R}(u)$, with $\beta_{1}>0$ and $\beta_{2}<0$.

For the high (positive) discretion region, we have the corresponding solution $V^{D}(u)=A_{1 h} e^{\beta_{1} u}+A_{2 h} e^{\beta_{2} u}+S^{D}(u)$.

The particular solution $S^{D}(u)$ turns out to be the value of discretion forever, so that the two exponential terms are the value of the option to commit. (See also Dixit and Pindyck [1994, chapter 6, section 2].) For very large shocks $u$ approaching infinity, it becomes exceedingly unlikely that the regulator will ever commit (recall that it prefers discretion for large shocks), and so the value of that option approaches zero. This means the term with the positive exponent, $\beta_{1}$, must vanish for large $u$, implying that $A_{1 h}$ must be zero. This leads to the simplified expression for the value function in the high (positive) discretion region:

positive cost of recommitment and allowing delay in recommitment. In another sense, those models are more general, in that they allow more general state-contingent rules. We prefer to focus on the dynamics.

${ }^{7}$ The particular solution is all that would change if we used a form of costs other than quadratic. 
(4) $V_{h}^{D}(u)=A_{2 h} e^{\beta_{2} u}+S^{D}(u)$.

After employing a similar argument for the lower (negative) discretion region, we have (5) $V_{l}^{D}(u)=A_{1 l} e^{\beta_{1} u}+S^{D}(u)$.

Four boundaries define the regions. Two boundaries determine when the regulator "weasels" out of rules and adopts discretion, one at the upper boundary $\bar{u}_{W}$ and one at the lower boundary $\underline{u}_{W}$. The other two boundaries determine when a discretionary regulator commits to rules, entering the commitment region from above, $\bar{u}_{C}$, or from below, $\underline{u}_{C}$.

With the general form of the value function in hand, we can find the boundary values by imposing the value-matching and smooth-pasting conditions. For example, at the upper commitment boundary, the value of continuing in discretion just equals the value of adopting rules and paying the cost to commit:

(6) $V_{h}^{D}\left(\bar{u}_{c}\right)=V^{R}\left(\bar{u}_{c}\right)-C$.

Likewise, the smooth pasting conditions impose equality on the derivatives of the value functions:

(7) $V_{h}^{\prime D}\left(\bar{u}_{c}\right)=V^{\prime R}\left(\bar{u}_{c}\right)$.

This is repeated for each boundary, producing eight equations (one value matching and one smooth pasting condition for each boundary) in eight unknowns (four boundaries and four undetermined coefficients). The appendix sets out these equations and proves the existence and uniqueness of the solution.

Numerical Solution and Comparative Statics 
As frequently happens in the stochastic control literature, closed-form solutions do not seem to exist for this problem, and we resort to numerical methods. Gauss NLSYS was able to solve the eight simultaneous equations, though convergence of the algorithm was sensitive to starting values. The actual numerical solutions are less interesting than the comparative static results. Starting from a base case of $C=W=0.01, \alpha=0$, $\sigma^{2}=0.01$, and $r=0.02$, figures 1 through 4 depict the solutions under a variety of parameter variations.

Figure 1 highlights the importance of history. It shows a solution and one sample path for the shocks, the commitment and weasel boundaries, and uses shading to indicate the time spent committed to rules. Because the weasel and commit boundaries differ, in some states of the economy (levels of $u$ ) current policy depends on past policy. For anything above the upper commit line and below the upper weasel line, a regulator committed to rules sticks with rules and a regulator using discretion sticks with discretion. Quite apparently, then, it is incorrect to judge policy simply on the current state of the economy, and particularly inappropriate to naively contrast current policy with past policies at a similar state of the economy or stage of the business cycle. In a word, our model predicts policy hysteresis. This shifting reemphasizes a point stressed by Flood and Garber (1984) in their work on the gold standard: To evaluate a policy rule, one must analyze the entire dynamic policy sequence, including periods where discretion reigns.

Implicit in the hysteresis is something so obvious that it might escape notice--that the policymaker switches from rules to discretion, and from discretion to rules, over time. Regimes shift. Discretion, commitment, and weaseling out of commitment will all occur. 
Figure 2 plots the commitment and weasel boundaries as the commitment cost changes, keeping the weasel cost fixed at 0.01 . Notice that for any particular commitment cost, the regulator adopts rules for "small" shocks on either side of zero. For larger shocks, the Fed adopts discretion. This is a natural consequence of the quadratic payoff function.

Another prominent feature is that the weasel boundary is farther out than the commit boundary. Were there no cost of switching between regimes, the boundaries would be the same, at $V_{h}^{D}(u)=V^{R}(u)$, where the expected gain from continuing discretion just matches the expected gain from using rules. ${ }^{8}$ Adding a commitment cost drives a wedge between the two value functions and requires that the regulator gain even more from rules. This means moving the boundary farther into the area where rules are preferred, that is, closer to zero. Similarly, a cost to backing out of rules means shifting the boundary even farther into the area where discretion is preferred, that is, away from zero. Hence the weasel boundary is farther out than the commit boundary.

Figure 2 shows that the greater the cost of commitment, the less likely the regulator is to commit. As the cost increases, the relative benefits of rules over discretion must also increase, and so the commitment boundary shrinks towards zero. For a high enough cost, commitment never occurs.

One other more practical advantage of the continuous-time formulation lies in its ability to allow easy exploration of a broad range of questions, like changes in entry and exit costs and variability of shocks.

\footnotetext{
${ }^{8}$ In the zero-cost case, first-order conditions (value matching and smooth pasting) have multiple solutions, including the solution to the original problem. For all positive costs, the solution is unique.
} 
Figure 3 illustrates what happens when the weasel cost varies. As the cost of switching out of rules rises, it takes an increasingly large benefit of discretion over rules to make the switch worthwhile, and so the weasel boundary increases. Notice that in figures 2 and 3 , a rise in commitment cost primarily moves the commitment boundary, and a rise in weaseling cost primarily moves the weasel boundary. This reflects the relatively low variance of $u$. At the commitment boundary, it is improbable that the process will soon wander as far as the weasel boundary, and so this has little weight in the optimization problem, making the weasel boundary almost perfectly flat. When the boundaries are close, as for small values of $C$ and $W$, both boundaries move more noticeably with an increase in either cost. A higher variance for $u$ makes the effect more pronounced. Figure 4 illustrates a different exercise, in which the variance of the Brownian motion governing the shocks is increased. As the variance rises, the commitment boundaries decrease and the weasel boundaries increase. This is a consequence of the options component of the decision. As the variance rises, so too does the option value of not switching. For example, in the discretion region, a high variance means there is a good chance of moving deeper into that region in the near future, but also a good chance of moving into the rules region. The bad news principle enters here. Ending up deep in the discretion region means regretting the commitment to rules. Ending up deep in the rules region means committing to rules when you get there, so committing today doesn't help. Thus, the high variance makes commitment less likely, and the commitment boundary decreases correspondingly. With a high enough variance, the regulator never commits.

Expected Time in Regime 
Since we propose a model with discrete regime shifts, how long the current policy regime is expected to last is critical in applications like asset pricing, where agents must look into the future. For example, monetary policy conducted under discretion may result in a higher inflation rate than policy conducted under rules. Most bond traders--and academics studying the term structure of interest rates--concede the influence of monetary policy. Most would also concede frustration in understanding that influence. At times modest increases in the federal funds rate lead to sharp increases in long rates; at other times modest changes provoke modest changes. ${ }^{9}$ Thinking about policymakers as entering and exiting commitment, with its associated nonlinearities and hysteresis, can shed some light--and one day may even yield some quantitative evidence--on the matter.

To obtain an idea of how the expected time in a regime behaves, we set up the following simulation. We let the underlying shock follow Brownian motion with a variance of 0.1 . We sampled this process 120 times at monthly intervals, assuming commitment boundaries of +2 and -2 and weasel boundaries of +3 and -3 . This was meant to capture the idea that the policymaker periodically, but not continually, reviews policy based on the indicators of the underlying economy. For a given starting point, we generated 1,000 runs of the Brownian motion path, keeping track (by month) of when the path was in the rules and the discretion region (which is obviously path dependent). Averaging over the 1,000 runs gives an estimate of the expected fraction of time spent in each region over the next 10 years. Figure 5 reports the results. The $\mathrm{X}$-axis shows the starting value for the simulation, and the Y-axis shows the fraction of time spent in discretion. For example, if the current value of the underlying shock is 1.5 , the expected

\footnotetext{
${ }^{9}$ See Goodfriend (1993) or Campbell (1995) for amplification of this point.
} 
fraction of time in discretion is only 0.04 ( or 4.8 months out of 10 years). In other words, the amount of time expected to be spent in discretion over the next 10 years is trivial, given a starting point this far into the rules region. The figure reports two numbers for starting values between 2 and 3, depending on whether the starting value is assumed to be in the rules or the discretion region.

If, as mentioned above, the discretion regime results in a higher inflation rate, the data shown in figure 5 can easily be translated into a numerical inflation premium. Say that rules produce zero inflation and discretion produces constant inflation of 10 percent. Then the average expected inflation over the next 10 years is 0.4 percent when the underlying state is 1.5 , but it rises rapidly thereafter.

Figure 5 emphasizes and quantifies the importance of hysteresis for forwardlooking variables. For a starting value of 2.5 in the rules region, the policymaker expects to be in discretion only about one-third of the time over the next 10 years. If that same value of 2.5 is in the discretion region, the corresponding number is about two-thirds. This implies that expectations are asymmetric during increases and decreases of the shocks. Equally important, expectations can change quickly once the shocks approach a boundary. The expected time in discretion changes from 0.001 to 0.009 in moving from 0 to 1 , but changes from 0.16 to 0.86 in moving from 2 to 3 . The relation between the underlying shock and the result is decidedly nonlinear.

These results imply that inflationary expectations--and thus long-term interest rates--can change dramatically without a shift in policy, as people anticipate that a new policy regime is more likely. These shifts depend sensitively on the underlying state of the economy and on the current policy regime. 


\section{Conclusion}

Viewing commitment as irreversible investment has two major advantages: It provides a new perspective on questions of commitment, rules, and discretion, clearing up some troubling aspects of the literature. Equally important, that perspective represents a useful new direction for the irreversible investment literature. It applies quite naturally to strategic interactions--games--without the need for drastic revision. Though we don't wish to downplay the difficulties arising in each specific case, such as dealing with different stochastic processes or multiple boundaries, the basic concepts and techniques of investment under uncertainty gain a wider applicability.

Thus, besides providing new answers to old questions, this approach also raises new questions. By making the commitment versus discretion problem more amenable to attack by the techniques of financial economics, a new set of tools (and problems) naturally arises. For example, policy commitment should matter for asset prices; consider a shift in monetary policy, a poison pill being activated, or a shift in bank closure policy. Conversely, asset prices may allow us to estimate commitment probabilities and other fundamentals of the model. What this means that we have a powerful set of techniques ready to address significant questions in banking, finance, and economics. 


\section{Appendix : Theoretical Solution}

\section{Solving for the Value Functions}

This part of the appendix solves the differential equations of section III to find the value functions. For reference, those two equations are

$$
\frac{1}{2} \sigma^{2} V_{u u}^{D}+\alpha V_{u}^{D}-r V^{D}=-P^{D}
$$

for the interior of the discretion region and

$$
\frac{1}{2} \sigma^{2} V_{u u}^{R}+\alpha V_{u}^{R}-r V^{R}=-P^{R}
$$

for the interior of the rules region.

Both are equations of the form

$$
a y^{\prime \prime}(x)+b y^{\prime}(x)+c y(x)=q_{0}+q_{1} \mathrm{x}+q_{2} x^{2} \equiv Q(x) .
$$

The solutions to the homogenous part are

$$
y(x)=A_{1} e^{\beta_{1} x}+A_{2} e^{\beta_{2} x},
$$

where $\beta_{i}$ are solutions to the characteristic equation

$$
a \lambda^{2}+b \lambda+c=0 .
$$

Since $c<0$ in our application, we have one positive and one negative root. Let $\beta_{2}<0<\beta_{1}$. The particular solution can be a quadratic:

$$
\begin{gathered}
y(x)=s_{0}+s_{1} x+s_{2} x^{2} \\
y^{\prime}(x)=s_{1}+2 s_{2} x \\
y^{\prime \prime}(x)=2 s_{2} .
\end{gathered}
$$

Substituting yields

$$
\begin{gathered}
q_{0}+q_{1} x+q_{2} x^{2}=a\left(2 s_{2}\right)+b\left(s_{1}+2 s_{2} x\right)+c\left(s_{0}+s_{1} x+s_{2} x^{2}\right) \\
=\left(2 a s_{2}+b s_{1}+c s_{0}\right)+\left(2 b s_{2}+c s_{1}\right) x+\left(c s_{2}\right) x^{2} .
\end{gathered}
$$

Matching coefficients yields

$$
\begin{gathered}
s_{2}=\frac{q_{2}}{c} \\
s_{1}=\frac{q_{1}-2 b s_{2}}{c}
\end{gathered}
$$




$$
s_{0}=\frac{q_{2}-b s_{1}-2 a s_{2}}{c} .
$$

Since $Q(x)$ is either $-P^{D}$ or $-P^{R}$, we have one particular solution for discretion and one for rules (call them $S^{D}$ and $S^{R}$ ).

There are three regions: high- $u$ discretion, low- $u$ discretion, and rules. Take these in order. For high- $u$ discretion the solution is

$$
V^{D}(u)=A_{1 h} e^{\beta_{1} u}+A_{2 h} e^{\beta_{2} u}+S^{D}(u) .
$$

Substituting $s_{0}, s_{1}$, and $s_{2}$ into the quadratic particular solution makes it clear that $S^{D}(u)$ turns out to be the value of discretion forever, so the other terms are the value of the option to commit. (See Dixit and Pindyck [1984, chapter 6, section 2]). As $u \rightarrow \infty$ this option becomes worthless, so we need to have $A_{1 h}=0$ (since $\left.\beta_{1}>0\right)$. So our solution is equation (4) of the paper):

$$
V_{h}^{D}(u)=A_{2 h} e^{\beta_{2} u}+S^{D}(u)
$$

For low- $u$ discretion we need $A_{21}=0$. Otherwise, the value option to commit explodes as we get farther in the negative direction from the point at which we would want to commit. So, in the low- $u$ discretion region, we have equation (5) of the paper:

$$
V_{l}^{D}(u)=A_{1 l} e^{\beta_{1} u}+S^{D}(u) .
$$

The rules region is bounded, so neither option term drops out, and the solution is equation (3) of the paper:

$$
V^{R}(u)=B_{1} e^{\beta_{1} u}+B_{2} e^{\beta_{2} u}+S^{R}(u) .
$$

The value function must also satisfy the following value-matching and smoothpasting conditions:

$$
\begin{gathered}
V_{h}^{D}\left(\bar{u}_{c}\right)=V^{R}\left(\bar{u}_{c}\right)-C \\
V_{l}^{D}\left(\underline{u}_{c}\right)=V^{R}\left(\underline{u}_{c}\right)-C \\
V^{R}\left(\bar{u}_{w}\right)=V_{h}^{D}\left(\bar{u}_{w}\right)-W \\
V^{R}\left(\underline{u}_{w}\right)=V_{l}^{D}\left(\underline{u}_{w}\right)-W \\
V_{h}^{D^{\prime}}\left(\bar{u}_{c}\right)=V^{R^{\prime}}\left(\bar{u}_{c}\right) \\
V_{l}^{D^{\prime}}\left(\underline{u}_{c}\right)=V^{R^{\prime}}\left(\underline{u}_{c}\right)
\end{gathered}
$$




$$
\begin{aligned}
& V^{R^{\prime}}\left(\bar{u}_{w}\right)=V_{h}^{D^{\prime}}\left(\bar{u}_{w}\right) \\
& V^{R^{\prime}}\left(\underline{u}_{w}\right)=V_{l}^{D^{\prime}}\left(\underline{u}_{w}\right) /
\end{aligned}
$$

We have eight equations and eight unknowns: $A_{1}, A_{2 h}, B_{1}, B_{2}, \bar{u}_{c}, \underline{u}_{c}, \bar{u}_{w}$, and $\underline{u}_{w}$.

\section{Existence and Uniqueness of Solutions}

To establish the existence and uniqueness of the solution, we use a variation on the approach used by Dixit (1989b, unpublished appendix).

\section{Preliminaries}

First, we define two functions that measure the difference between the value functions (analogues of Dixit's $G(P)$ function) for the upper and lower boundary pairs:

$$
\begin{aligned}
H(u) & =V^{R}(u)-V_{h}^{D}(u) \\
& =B_{1} e^{\beta_{1} u}+B_{2} e^{\beta_{2} u}+S^{R}(u)-A_{2 h} e^{\beta_{2} u}-S^{D}(u) \\
& =B_{1} e^{\beta_{1} u}+D_{2} e^{\beta_{2} u}+Q(u) \text { and } \\
L(u) & =V^{R}(u)-V_{l}^{D}(u) \\
& =B_{1} e^{\beta_{1} u}+B_{2} e^{\beta_{2} u}+S^{R}(u)-A_{1 l} e^{\beta_{1} u}-S^{D}(u) \\
& =D_{1} e^{\beta_{1} u}+B_{2} e^{\beta_{2} u}+Q(u),
\end{aligned}
$$

where $D_{1}=B_{1}-A_{1 l}, D_{2}=B_{2}-A_{2 h}$, and $Q(u)=S^{R}(u)-S^{D}(u) . S^{R}$ and $S^{D}$ are the particular solutions for the differential equations that lead to the value functions.

Next, we need to establish that $Q(u)$ is convex. Convexity follows from our assumption that the rules loss function is more convex than the discretion loss function and from the formulae for $S^{R}$ and $S^{D}$.

The introduction of $D_{i}$ separates the problem of finding the upper boundaries from that of finding the lower boundaries. Without loss of generality, we consider only the upper boundaries, concentrating on the function $H\left(u ; B_{1}, D_{2}\right)$. Where there is no chance of confusion, we suppress the dependence of $H$ on its parameters and write $H(u)$. Existence 
Consider the upper boundaries. We define a sequence of functions $H_{i}$ (and the corresponding $B_{1}^{i}$ and $D_{2}^{i}$ ), which converge to a function $H$ that which satisfies the smooth-pasting and value-matching conditions. Let

$$
H_{0}(u)=Q(u) .
$$

Keeping $D_{2}=0$, set $B_{1}^{1}$ so that

$$
H_{1}(u)=B_{1}^{1} e^{\beta_{1} u}+H_{0}(u)
$$

is tangent to the horizontal line at $+W$. This can be accomplished by some $B_{1}^{1}<0$, because $H_{1}^{\prime}(u)$ increases without bound as we increase $B_{1}^{1}$ and decreases without bound as we decrease $B_{1}^{1}$. This produces a local maximum, since $B_{1}^{1}<0$. (Note that we cannot start with $D_{2}$, because $Q$ may not intersect $-C$.)

Now let

$$
H_{2}(u)=D_{2}^{2} e^{\beta_{2} u}+H_{1}(u) .
$$

$H_{2}$ is increasing in $D_{2}^{2}$, and $H_{2}^{\prime}$ is decreasing (since $\beta_{2}<0$ ) without bound in $D_{2}^{2}$. Increase $D_{2}^{2}$ to make $H_{2}$ tangent to $-C$. This will be a local minimum. Notice that this puts $H_{2}$ above $H_{1}$ at the point where $H_{1}$ is tangent to $+W$.

Now let

$$
H_{3}(u)=B_{1}^{3} e^{\beta_{1} u}+H_{2}(u) .
$$

Decrease $B_{1}^{3}$ to restore tangency with $+W$. Continue this process, thus generating the sequence.

Note that $H_{\mathrm{i}}$ goes off to $+\infty$ to the left of the tangencies and off to $-\infty$ to the right, as illustrated in figure A1. At each stage of this construction, there is an increasing segment of $H_{i}$ to the right of the local minimum and to the left of the local maximum. Let $\left\{B_{1 i}, D_{2 i}\right\}$ be the accumulation of the $B_{1}^{i}$ and $D_{2}^{i}$ in $H_{i}$. We have shown that this sequence is always moving northwest in $B_{1}-D_{2}$ space. This sequence cannot, by construction, go into a region where $H_{i}^{\prime}(u)<0$ for all $u$.

To show convergence, we need to bound the $\left\{B_{1 i}, D_{2 i}\right\}$ sequence. Notice that both exponential terms are downward-sloping, so we can find bounds on $B_{1 i}$ and $D_{2 i}$ separately. The only interval on which $H$ could possibly be increasing on the $B_{1}$ steps 
(that is, $H_{i}$ for odd $i$ ) is between the minimum of $Q$, denoted by $u^{Q}$, and the largest solution to $H_{1}^{\prime}(u)=\beta_{1} B_{1}^{1} e^{\beta_{1} u}+Q^{\prime}(u)=0$, denoted by $u^{*}$. (There are generally two solutions, because $Q^{\prime}(u)$ is linear while $-\beta_{1} B_{1}^{1} e^{\beta_{1} u}$ is convex. See figure A2.) We know that $u^{Q}<u^{*}$, because $\beta_{1} B_{1}^{1} e^{\beta_{1} u}>0$ and $B_{1}^{1}$ was chosen so that $H_{i}{ }^{\prime}\left(u^{*}\right)=0$. Hence, $\beta_{1} B_{1}^{1} e^{\beta_{1} u}$ intersects $Q^{\prime}(u)$. See figure A1.

A simple bounding argument will eliminate the possibility of an increasing $H$, even on this interval. For $u \in\left[u^{Q}, u^{*}\right]$, we have that $H_{i}^{\prime}(u)<0$ for $u>u^{*}$ and $i>1$ :

$$
\begin{aligned}
H_{i}^{\prime}(u) & =\beta_{1} B_{1 i} e^{\beta_{1} u}+\beta_{2} D_{2 i} e^{\beta_{2} u}+Q^{\prime}(u) \\
& <\left[\beta_{1} B_{1}^{1} e^{\beta_{1} u}+Q^{\prime}(u)\right]+\beta_{2} D_{2 i} e^{\beta_{2} u} \\
& <\beta_{1} B_{1}^{1} e^{\beta_{1} u}+Q^{\prime}(u) \\
& <\beta_{1} B_{1}^{1} e^{\beta_{1} u^{*}}+Q^{\prime}\left(u^{*}\right) \\
& =H_{1}^{\prime}\left(u^{*}\right)=0 .
\end{aligned}
$$

The first inequality comes from the fact that $\left\{B_{1 i}\right\}$ is a decreasing sequence of negative numbers. The second follows from the fact that $D_{2 i}>0$ with $\beta_{2}<0$. The third comes from the fact that $-\beta_{1} B_{1}^{1} e^{\beta_{1} u}$ cuts $Q^{\prime}(u)$ from below at $u^{*}$, so that both increase on $\left[u^{Q}\right.$, $u^{*}$. Again, see figure A2. On $\left[u^{Q}, u^{*}\right], e^{\beta_{1} u}$ and $e^{\beta_{2} u}$ are minimized and maximized, respectively, at $u^{Q}$, since both are monotonic. Similarly, the slope of $Q$ is maximized at $u^{*}$.

Hence, there can be no increasing portion of $H_{i}(u)$ if

$$
\beta_{1} B_{1} e^{\beta_{1} u}+Q^{\prime}\left(u^{*}\right)<0
$$

for all $u \in\left[u^{Q}, u^{*}\right]$. This condition holds if

$$
B_{1}<\frac{-Q^{\prime}\left(u^{*}\right)}{\beta_{1} e^{\beta_{1} u}}<\frac{-Q^{\prime}\left(u^{*}\right)}{\beta_{1} e^{\beta_{1} u^{q}}}=\text { negative constant }
$$

Similarly, for the $D_{2}$ steps $\left(H_{i}\right.$ for even $i$ ) there can be no increasing portion of $H_{i}(u)$ on $\left[u^{Q}, u^{*}\right]$ if

$$
\beta_{2} D_{2} e^{\beta_{2} u}+Q^{\prime}\left(u^{*}\right)<0
$$

or 


$$
D_{2}<\frac{-Q^{\prime}\left(u^{*}\right)}{\beta_{2} e^{\beta_{2} u}}<\frac{-Q^{\prime}\left(u^{*}\right)}{\beta_{2} e^{\beta_{2} u^{Q}}}=\text { positive constant }
$$

Therefore, the sequence (which is moving northwest) is bounded in the region $0>B_{1}>$ negative constant, $0<D_{2}<$ positive constant.

\section{Uniqueness}

Recall that the definition of $D_{2}$ above reduced the problem to separate sets of four equations and four unknowns, two boundaries (two values of $u$ ) and two undetermined constants. The uniqueness proof first shows that, for any given value of the constants, the boundaries are unique, and then shows that the constants are unique.

Define $\bar{u}_{c}\left(B_{1}, D_{2}\right)$ and $\bar{u}_{w}\left(B_{1}, D_{2}\right)$ as the respective values of $u$ where the local minimum and maximum of $H\left(u ; B_{1}, D_{2}\right)$ occur. First, we show that there can be only one minimum $\bar{u}_{c}\left(B_{1}, D_{2}\right)$, and one maximum $\bar{u}_{w}\left(B_{1}, D_{2}\right)$ for $H$, given $B_{1}$ and $D_{2}$.

Lemma: For given values of $B_{1}<0$ and $D_{2}>0, H^{\prime}\left(u ; B_{1}, D_{2}\right)=0$ has at most three solutions.

Proof: Write $H^{\prime}=0$ as

$$
-Q^{\prime}(u)=\beta_{1} B_{1} e^{\beta_{1} u}+\beta_{2} D_{2} e^{\beta_{2} u} .
$$

Since $Q$ is convex, the LHS is a decreasing line. The RHS is downward-sloping, convex to the left, and concave to the right -- like a cotangent function. Obviously, there will be no more than three solutions.

Given the shape of $H$--that is, $\lim _{u \rightarrow-\infty} H(u)=+\infty, \lim _{u \rightarrow+\infty} H(u)=-\infty$ (again see figure A1)--solutions to $H^{\prime}(u)=0$ come in pairs. Thus, have more than one minimum and one maximum, we would need at least four solutions to $H^{\prime}=0$. But the lemma shows that we can have at most three, and since we have already proven existence, we know that exactly two solutions exist, a unique maximum and a unique minimum. This implies that $\bar{u}_{c}\left(B_{1}, D_{2}\right)$ and $\bar{u}_{w}\left(B_{1}, D_{2}\right)$ are well defined, single-valued functions.

To complete the proof, we show that $B_{1}$ and $D_{2}$ are unique. The proof proceeds by contradiction:

Define 


$$
\begin{aligned}
& \Gamma_{c}\left(B_{1}, D_{2}\right) \equiv B_{1} e^{\beta_{1} \bar{u}_{c}\left(B_{1}, D_{2}\right)}+D_{2} e^{\beta_{2} \bar{u}_{c}\left(B_{1} D_{2}\right)}+Q\left(\bar{u}_{c}\left(B_{1}, D_{2}\right)\right) \\
& \Gamma_{w}\left(B_{1}, D_{2}\right) \equiv B_{1} e^{\beta_{1} \bar{u}_{w}\left(B_{1} D_{2}\right)}+D_{2} e^{\beta_{2} \bar{u}_{w}\left(B_{1} D_{2}\right)}+Q\left(\bar{u}_{w}\left(B_{1}, D_{2}\right)\right)
\end{aligned}
$$

In this notation, the value-matching conditions are

$$
\begin{aligned}
& \Gamma_{c}\left(B_{1}, D_{2}\right)=-C \\
& \Gamma_{w}\left(B_{1}, D_{2}\right)=W .
\end{aligned}
$$

Also,

$$
\begin{aligned}
\frac{\partial \Gamma_{c}}{\partial B_{1}} & =H_{u} \frac{\partial \bar{u}_{c}}{\partial B_{1}}+H_{B_{1}} \\
& =H_{B_{1}} \\
& =e^{\beta_{1} \bar{u}_{c}\left(B_{1}, D_{2}\right)} .
\end{aligned}
$$

$H_{u}=0$ because $\bar{u}_{c}\left(B_{1}, D_{2}\right)$ and $\bar{u}_{w}\left(B_{1}, D_{2}\right)$ are chosen so that the smooth-pasting conditions hold when $H$ is evaluated at $\bar{u}_{c}\left(B_{1}, D_{2}\right)$ or $\bar{u}_{w}\left(B_{1}, D_{2}\right)$. Similarly,

$$
\begin{aligned}
& \frac{\partial \Gamma_{c}}{\partial D_{2}}=e^{\beta_{2} \bar{u}_{c}\left(B_{1}, D_{2}\right)} \\
& \frac{\partial \Gamma_{w}}{\partial B_{1}}=e^{\beta_{1} \bar{u}_{w}\left(B_{1}, D_{2}\right)} \\
& \frac{\partial \Gamma_{w}}{\partial D_{2}}=e^{\beta_{2} \bar{u}_{w}\left(B_{1}, D_{2}\right)} .
\end{aligned}
$$

Now we show that a second solution cannot exist. Note that if $\left(B_{1}^{\prime}, D_{2}^{\prime}\right)$ is a second solution to the value-matching and smooth-pasting conditions with $B_{1}^{\prime}>B_{1}$, we must have $D_{2}^{\prime}<D_{2}$ to maintain the value-matching conditions: $\Gamma_{c}\left(B_{1}^{\prime}, D_{2}^{\prime}\right)=-C$ and $\Gamma_{w}\left(B_{1}^{\prime}, D_{2}^{\prime}\right)=W$.

Let $b=B_{1}^{\prime}-B_{1}>0$ and $d=D_{2}^{\prime}-D_{2}<0$. The line segment joining the solutions is $\left(B_{1}+t b, D_{2}+t d\right)$. We have

$$
\begin{aligned}
\frac{d}{d t} \Gamma_{c}\left(B_{1}+t b, D_{2}+t d\right) & =b \frac{\partial \Gamma_{c}}{\partial B_{1}}+d \frac{\partial \Gamma_{c}}{\partial D_{2}} \\
& =b e^{\beta_{1} \bar{u}_{c}\left(B_{1}+t b, D_{2}+t d\right)}+d e^{\beta_{2} \bar{u}_{c}\left(B_{1}+t b, D_{2}+t d\right)}
\end{aligned}
$$

Given our hypothesis that $\Gamma_{c}\left(B_{1}, D_{2}\right)=\Gamma_{c}\left(B_{1}^{\prime}, D_{2}^{\prime}\right)=C$, 


$$
\begin{aligned}
0 & =\Gamma_{c}\left(B_{1}^{\prime}, D_{2}^{\prime}\right)-\Gamma_{c}\left(B_{1}, D_{2}\right) . \\
& =\int_{0}^{1}\left(b e^{\beta_{1} \bar{u}_{c}\left(B_{1}+t b, D_{2}+t d\right)}+d e^{\beta_{2} \bar{u}_{c}\left(B_{1}+t b, D_{2}+t d\right)}\right) d t .
\end{aligned}
$$

Similarly,

$$
\begin{aligned}
0 & =\Gamma_{w}\left(B_{1}^{\prime}, D_{2}^{\prime}\right)-\Gamma_{w}\left(B_{1}, D_{2}\right) \\
& =\int_{0}^{1}\left[b e^{\beta_{1} \bar{u}_{w}\left(B_{1}+t b, D_{2}+t d\right)}+d e^{\beta_{2} \bar{u}_{w}\left(B_{1}+t b, D_{2}+t d\right)}\right] d t .
\end{aligned}
$$

Again, because of the shape of $H$,

$\bar{u}_{c}\left(B_{1}, D_{2}\right)<\bar{u}_{w}\left(B_{1}, D_{2}\right) \Rightarrow e^{\beta_{1} \bar{u}_{c}\left(B_{1}, D_{2}\right)}<e^{\beta_{1} \bar{u}_{w}\left(B_{1}, D_{2}\right)}$ and $e^{\beta_{2} \bar{u}_{c}\left(B_{1}, D_{2}\right)}>e^{\beta_{2} \bar{u}_{w}\left(B_{1}, D_{2}\right)}$.

Recall that $b>0$ and $d<0$. Subtracting the two integrals, we get

$$
0=\int_{0}^{1}\left[b\left(e^{\beta_{1} \bar{u}_{c}\left(B_{1}, D_{2}\right)}-e^{\beta_{1} \bar{u}_{w}\left(B_{1}, D_{2}\right)}\right)+d\left(e^{\beta_{2} \bar{u}_{c}\left(B_{1}, D_{2}\right)}-e^{\beta_{2} \bar{u}_{w}\left(B_{1}, D_{2}\right)}\right)\right] d t .
$$

The integrand is always negative, so the integral cannot be 0 . That is, both solutions satisfy the value-matching conditions only if they are identical.

Thus, $B_{1}$ and $D_{2}$ are unique, and so uniquely define $\bar{u}_{c}\left(B_{1}, D_{2}\right)$ and $\bar{u}_{w}\left(B_{1}, D_{2}\right)$, making the entire solution unique. 


\section{References}

Barro, Robert J., and David B. Gordon, "A Positive Theory of Monetary Policy in a Natural-Rate Model," Journal of Political Economy, vol. 91, no. 4 (August 1983), pp. 589-610.

Brams, Steven J., Superior Beings--If They Exist, How Would We Know?: Game Theoretic Implications of Omniscience, Immortality, and Incomprehensibility, Springer Verlag, 1983.

Campbell, John Y., "Some Lessons from the Yield Curve," Journal of Economic Perspectives, vol. 9, no. 3 (Summer 1995), pp. 129-52.

Dixit, Avinash, "Entry and Exit Decisions under Uncertainty," Journal of Political Economy, vol. 97, number 3 (June 1989a), pp. 620-38.

Dixit, Avinash K., "Appendices for Entry and Exit Decision Under Uncertainty" unpublished appendices to article in the Journal of Political Economy, June 1989b.

Dixit, Avinash K., and Robert S. Pindyck, Investment under Uncertainty, Princeton University Press, Princeton, 1994.

Flood, Robert P., and Peter Garber, "Gold Monetization and Gold Discipline," Journal of Political Economy, vol. 92, no. 1 (February 1984), pp. 90-107.

Flood, Robert P., and Peter Isard. "Monetary Policy Strategies," IMS Staff Papers, vol. 36, no. 3 (September 1989), pp. 612-32.

Goodfriend, Marvin, "Interest Rate Policy and the Inflation Scare Problem: 1979-1992,"

Federal Reserve Bank of Richmond, Economic Quarterly, vol. 79, no. 1 (1993), pp. 1-24.

Haubrich, Joseph G., and Joseph A. Ritter, "Dynamic Commitment and Imperfect Policy Rules,” Federal Reserve Bank of Cleveland, April 1995.

Kane, Edward J., The S\&L Insurance Mess: How Did It Happen? The Urban Institute Press, Washington, DC, 1989.

Lambson, Val Eugene, "Competitive Profits in the Long Run," Review of Economic Studies, vol. 59, no. 1 (January 1992), pp. 125-42.

Lohmann, Susanne. "Optimal Commitment in Monetary Policy: Credibility versus Flexibility," American Economic Review, vol. 82, no. 1 (March 1992), pp. 273-86.

Mailath, George J., and Loretta J. Mester, “A Positive Analysis of Bank Closure," Journal of Financial Intermediation, vol. 3, no. 3 (June 1994), pp. 272-99. 
McDonald, Robert and Daniel R. Siegel, "The Value of Waiting to Invest," Quarterly Journal of Economics, vol. 101, no. 4 (November 1986), pp. 707-27.

Obstfeld, Maurice and Kenneth Rogoff, "The Mirage of Fixed Exchange Rates," The Journal of Economic Perspectives, vol. 9, no. 4 (Fall 1995), pp. 73-96.

Pindyck, Robert S. "Irreversibility, Uncertainty, and Investment," Journal of Economic Literature, vol. 29, no 3 (September 1991), pp. 1110-48.

Pindyck, Robert S., "Optimal Economic Stabilization Policies under Decentralized Control and Conflicting Objectives," IEEE Transactions on Automatic Control, vol. AC22, no. 4 (August 1977), pp. 517-30.

Sargent, Thomas J., "Reaganomics and Credibility," Chapter 2 of Rational Expectations and Inflation, Harper and Row, Philadelphia, 1986.

Zarazaga, Carlos, "Argentina, Mexico, and Currency Boards: Another Case of Rules versus Discretion," Federal Reserve Bank of Dallas, Economic Review, Fourth Quarter 1995, pp. 14-24. 
Figure 1

\section{Entering and Exiting Commitment}

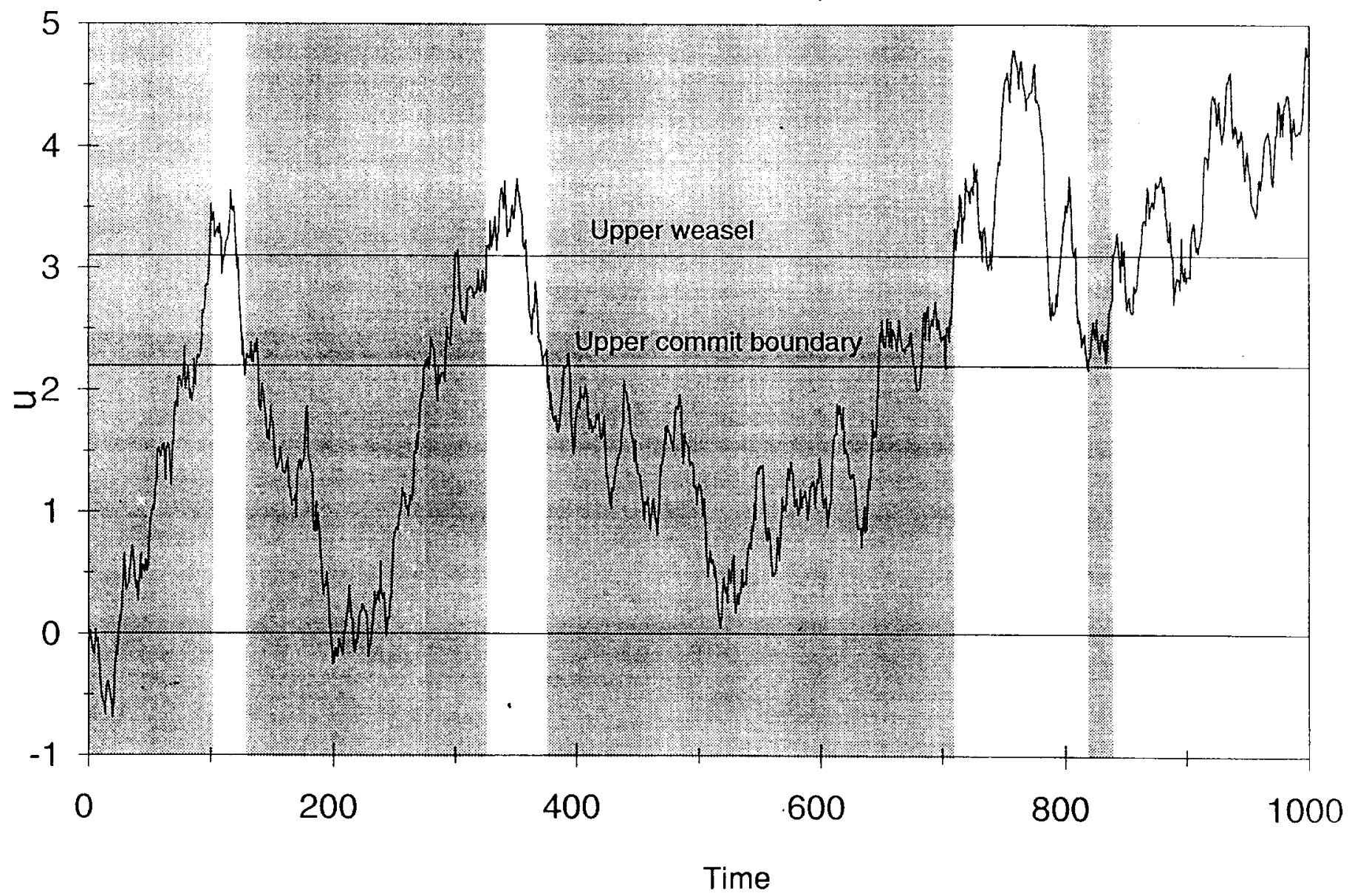

Note: Shaded areas are rules regimes.

Source: Authors' calculations. 


\section{Figure 2 \\ Effect of Commitment Cost Changes}

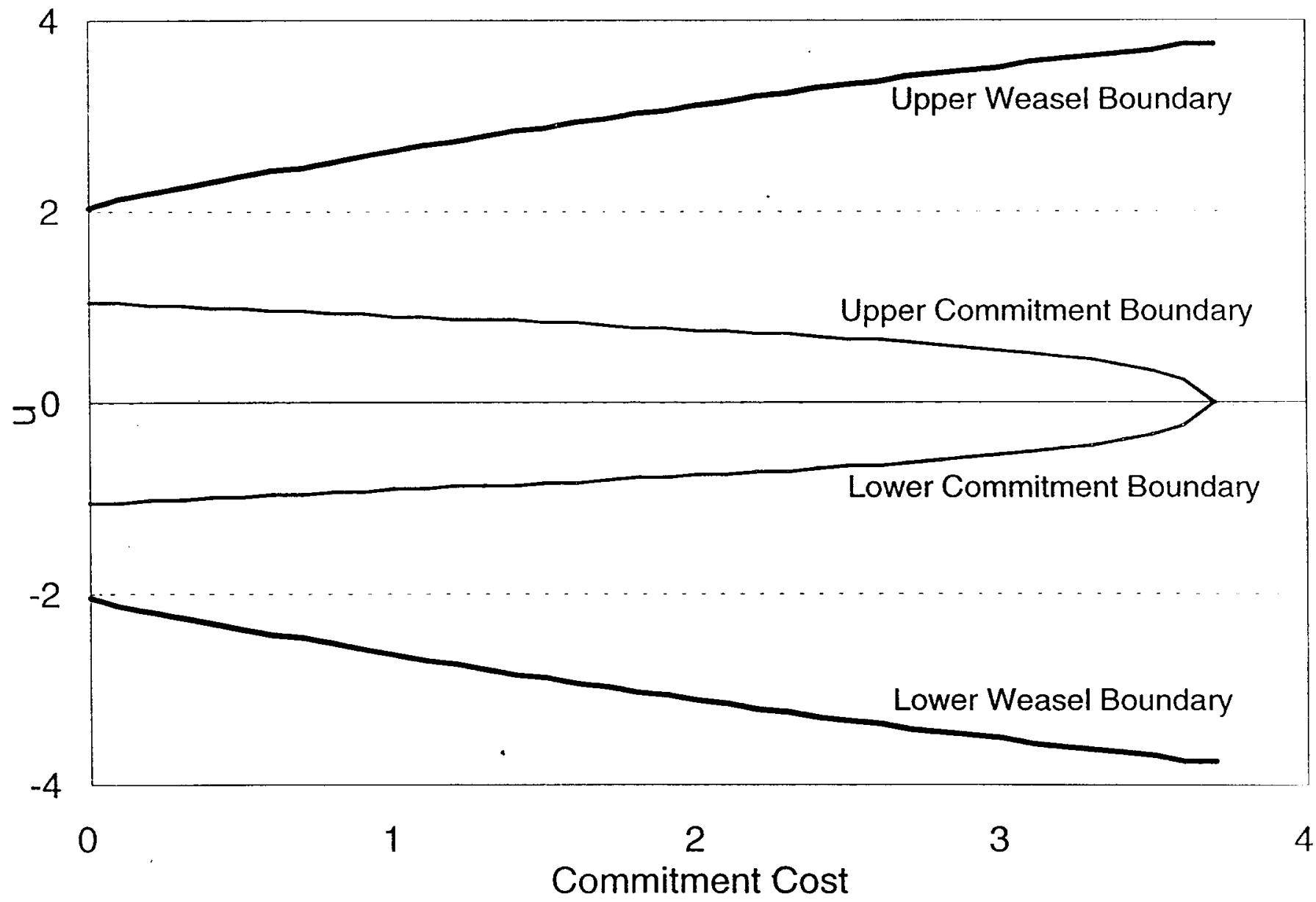


Figure 3

\section{Effect of Weasel Cost Changes}

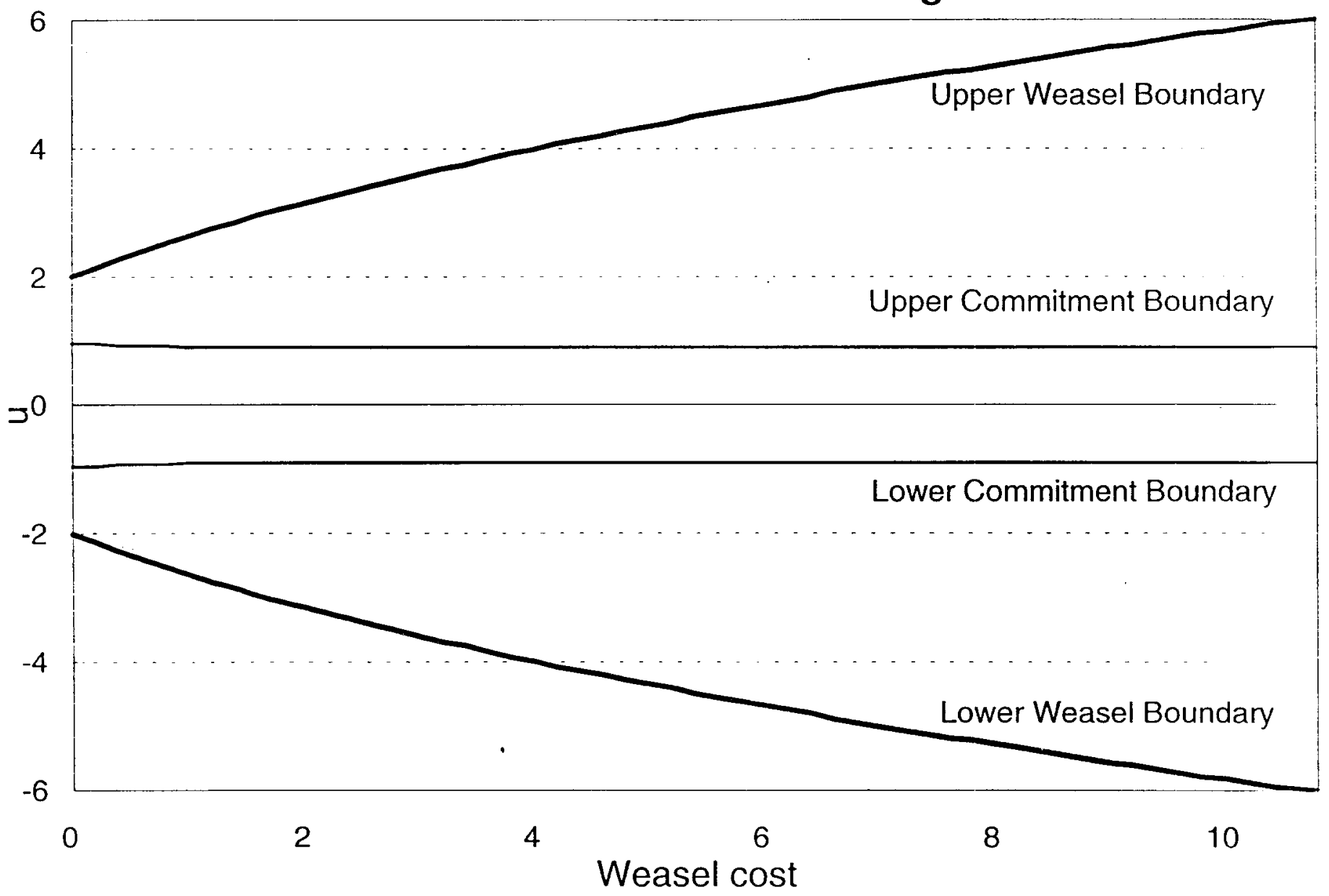

Source: Authors' calculations. 
Figure 4

\section{Effect of Shock Variance Changes}

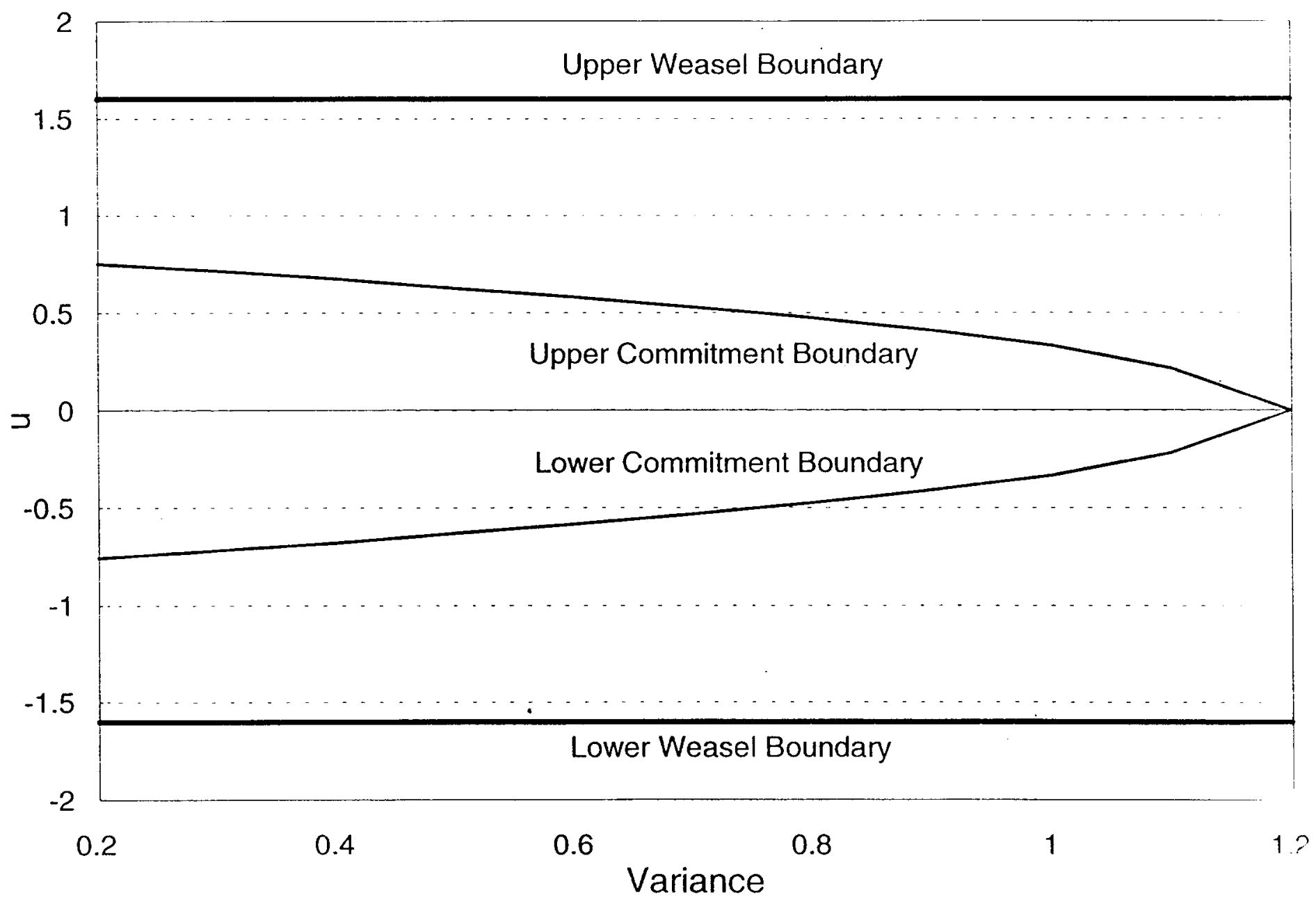




\section{Fraction of Time in Discretion}
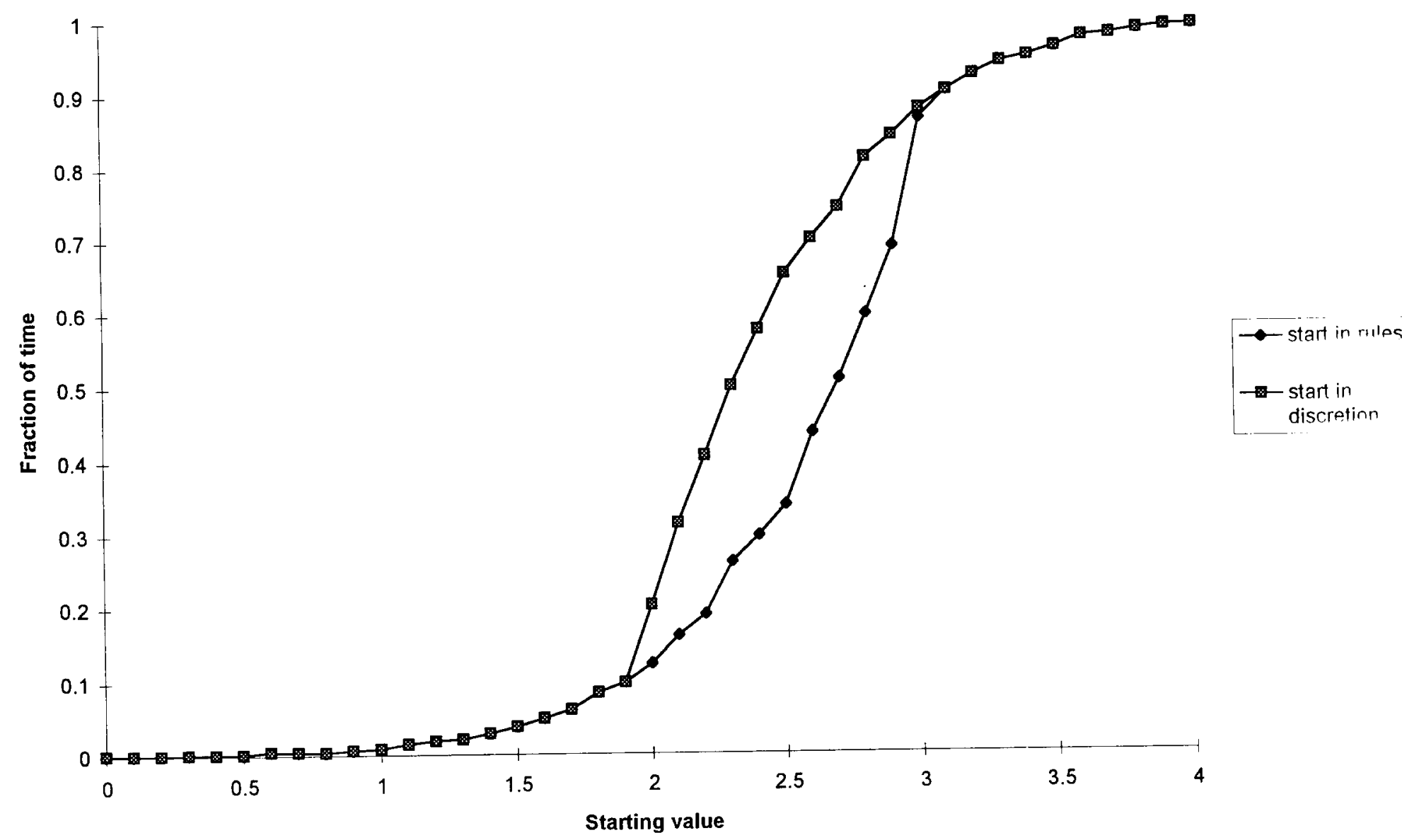


$$
\begin{gathered}
\text { Figure A-1 } \\
\text { Solution to } \\
H\left(u^{w}\right)=W, H\left(u^{c}\right)=-C, \\
H^{\prime}\left(u^{w}\right)=0, \text { and } H^{\prime}\left(u^{c}\right)=0
\end{gathered}
$$

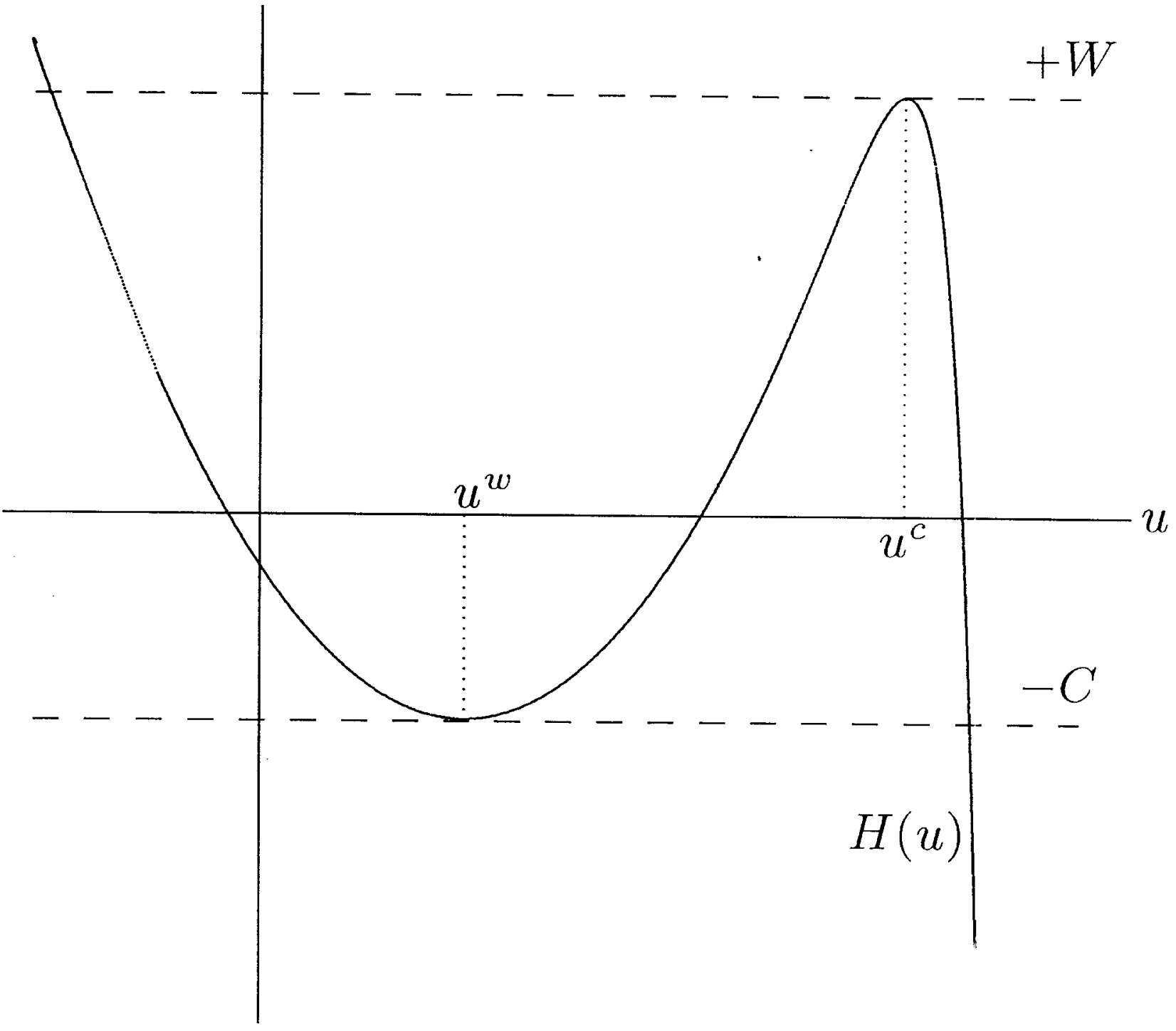


Figure $\mathrm{A}-2$

Solutions to $H_{1}^{\prime}(u)=0$

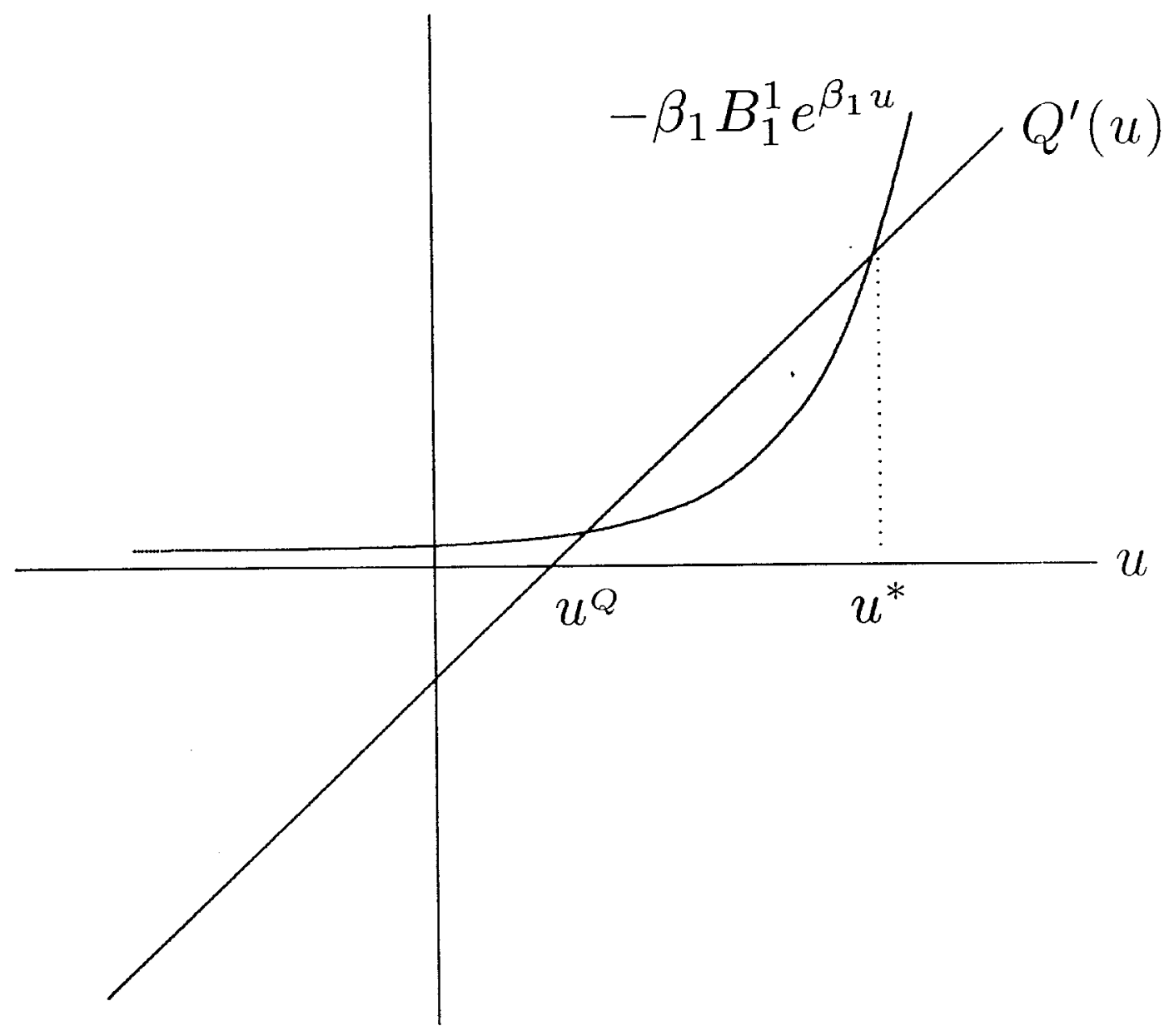

